\title{
Twin versus singleton pregnancies: the incidence, pregnancy complications, and obstetric outcomes in a Nigerian tertiary hospital
}

This article was published in the following Dove Press journal:

International Journal of Women's Health

26 July $201 \mathrm{I}$

Number of times this article has been viewed

\section{NJ Obiechina' \\ VE Okolie' \\ GU Eleje' \\ ZC Okechukwu' \\ OA Anemeje ${ }^{2}$}

'Department of Obstetrics and Gynaecology, Nnamdi Azikiwe University Teaching Hospital (NAUTH), Nnewi, Anambra State, Nigeria; ${ }^{2}$ Department of Family Medicine, Nnamdi Azikiwe University Teaching Hospital (NAUTH), Nnewi, Anambra State, Nigeria
Correspondence: GU Eleje

Department of Obstetrics and

Gynaecology, Nnamdi Azikiwe

University Teaching Hospital (NAUTH),

Nnewi; PMB 5025, Nnewi,

Anambra State, Nigeria

Tel +23 48068 I I7444

Email georgel2।@yahoo.com
Background: Twin pregnancy is associated with more pregnancy complications and poorer pregnancy outcome than singleton pregnancy. Hence periodic review is necessary to improve on the pregnancy outcome.

Objective: To determine the incidence and compare pregnancy complications and obstetric outcomes of twin pregnancies and singleton pregnancies.

Materials and methods: The twin pregnancies (study group) that were delivered at Nnamdi Azikiwe University Teaching Hospital (NAUTH), Nnewi, South-East Nigeria from 1st February 2005 to 31 st January 2010 were compared with singleton deliveries (control group) that occurred in the same hospital during the same period.

Results: A total of 3351 deliveries were conducted during the study period, of which 113 were twin deliveries, giving an incidence of 1:29.6 deliveries. Only 100 case files could be retrieved for analysis. The mean parities for the twins and singletons were $2.7 \pm 2.33$ weeks and $1.96 \pm 1.87$ weeks whereas the mean gestational age at delivery for twin and singleton deliveries were $34 \pm 5.2$ weeks and $38.7 \pm 2.4$ weeks respectively $(P<0.05)$. The mean birth weights were $3.14 \pm 0.73 \mathrm{~kg}$ and $2.3 \pm 1.0 \mathrm{~kg}$ for singletons and twins respectively $(P<0.05)$. Hypertensive disorders of pregnancy, cord prolapse, malpresentation, premature rupture of membranes, low Apgar scores, cesarean section rate, and perinatal death were significantly higher in twin pregnancies than in singleton.

Conclusion: The incidence of twin pregnancy over the study period was high and was significantly associated with more pregnancy complications and poorer obstetric outcomes. Close antenatal and intrapartum care are needed in order to improve outcome and decrease complications.

Keywords: twin pregnancy, singleton, low birth weight, perinatal death

\section{Introduction}

The incidence of twin pregnancies varies greatly among the different races of the world. ${ }^{1}$ It is most common among blacks of West African descent and least among Asian Mongolians. ${ }^{1,2}$ Even among a particular race, the incidence varies significantly among different ethnic groups.

A number of factors have been associated with increased incidence of twinning. These include advanced maternal age and the use of fertility drugs for induction of ovulation. ${ }^{1-6}$ Other factors include family history of twinning, maternal height and weight, previous history of twin delivery and diet. ${ }^{5,6}$

Although twin pregnancies are usually welcome, the excitement of a twin pregnancy can often be overshadowed by unforeseen complications. ${ }^{3}$ Twin pregnancies are 
associated with increased perinatal morbidity and mortality as well as a higher rate of cesarean deliveries. The obstetric complications include preterm labor, anemia, pregnancyinduced hypertension, postpartum hemorrhage, prematurity, and low birth weight. ${ }^{2,6}$ Periodic review of the outcome of twin pregnancy is necessary to scale up efforts aimed at reducing the associated complications.

This study aims to determine the incidence and compare maternal and fetal complications, as well as the obstetric outcome, of twin pregnancies in comparison with singletons at Nnamdi Azikiwe University Teaching Hospital (NAUTH), Nnewi, South-east Nigeria. These findings will facilitate the quality management and care of twin pregnancies and help improve obstetric outcomes.

\section{Material and methods}

This was a retrospective case-control study carried out at NAUTH, Nnewi, South-East Nigeria. The case files of 100 patients who had twin deliveries (study group) and singleton deliveries (control group) at NAUTH, Nnewi from 1st February 2005 to 31st January, 2010 were retrieved and studied. A thorough scrutiny of the delivery records of the obstetric unit as well as the records held by the medical records department of the hospital was done to identify these patients. The total number of deliveries during the study period was also determined. The data obtained from the case files were: maternal age, parity, gestational age at delivery, Apgar score, birth weight, and pregnancy complications. The control group included women with singleton deliveries within the same period of study, who delivered immediately after each of the twin deliveries. Permission to conduct this study was sought from and granted by the Nnamdi Azikiwe University Teaching Hospital Ethical Committee. Data analysis was done using Epi Info 2008 (v 3.5.1; Epi Info, Centers for Disease Control and Prevention, Atlanta, GA). Comparative analysis was done using Student's $t$-test, and odds ratio (OR) with 95\% confidence interval (CI) was calculated where applicable. A $P$-value $<0.05$ was taken as significant.

\section{Results}

Out of 3351 deliveries recorded within the study period, 113 were twin deliveries, giving an incidence of $3.37 \%$ or $1: 29.6$ deliveries. Among these 113 twin deliveries, only 100 case files were available for analysis.

As shown in Table 1, the mean maternal ages for the twin and singleton deliveries were $30 \pm 2.33$ years and $27 \pm 4.70$ years respectively. The mean parities for the twin and singleton deliveries were $2.7 \pm 2.33$ weeks
Table I Maternal and fetal characteristics of the study and control groups

\begin{tabular}{lrrrr}
\hline Characteristics & $\begin{array}{c}\text { Singleton } \\
\text { gestation }\end{array}$ & $\begin{array}{l}\text { Twin } \\
\text { gestation }\end{array}$ & t-test & P-value \\
\hline I Mean maternal & $27 \pm 4.70$ & $30 \pm 2.33$ & 4.40 & $<0.05$ \\
$\begin{array}{l}\text { age (years) } \\
\text { Mean parity }\end{array}$ & $1.96 \pm 1.87$ & $2.7 \pm 2.33$ & 2.48 & $<0.05$ \\
$\begin{array}{l}\text { Mean gestational } \\
\text { age (weeks) }\end{array}$ & $38.7 \pm 2.40$ & $34 \pm 5.20$ & 1.97 & $<0.05$ \\
$\begin{array}{l}\text { Mean birth } \\
\text { weight }(\mathrm{kg})\end{array}$ & $3.14 \pm 0.73$ & $2.3 \pm 1.00$ & 43.14 & $<0.05$ \\
\hline
\end{tabular}

and $1.96 \pm 1.87$ weeks whereas the mean gestational age at delivery for twins and singleton deliveries were $34 \pm 5.2$ weeks and $38.7 \pm 2.4$ weeks respectively. The mean birth weights for twin and singleton deliveries were $2.3 \pm 1 \mathrm{~kg}$ and $3.14 \pm 0.72 \mathrm{~kg}$. There were statistical significant differences $(P<0.05)$ between the two groups in all the parameters measured.

Table 2 shows the pregnancy complications in twin vs singleton deliveries. The risk of malpresentation was about three times higher in the twin pregnancies than the singleton pregnancies (OR: 2.98, CI: 1.04-9.70). There was a roughly seven times increased risk of cord prolapse/presentation (OR: 6.68, CI: 1.42-62.60) and a greater than three-fold increase in hypertensive disorders (OR: 3.21, CI: 1.8-23.6) in twin pregnancies. The risk of delivering a twin pregnancy via cesarean section was three times that of a singleton pregnancy (OR: 2.9, CI: 1.48-5.76). Also, the risk of premature rupture of membranes was increased by 4.5 times in twin pregnancies (OR: 4.42, CI: 1.62-13.90).

Table 2 Pregnancy complications in twin versus singleton deliveries

\begin{tabular}{lllll}
\hline Variables & Singleton & Twin & Odds ratio & $\mathbf{9 5 \%} \mathbf{C l}$ \\
\hline $\begin{array}{l}\text { I. Malpresentation } \\
\text { Yes }\end{array}$ & 6 & & & \\
No & 94 & 16 & 2.98 & $1.04-9.7$ \\
2. Cord presentation/prolapse & & & & \\
Yes & 2 & 12 & 6.68 & $1.42-62.6$ I \\
No & 98 & 88 & Ref & \\
3. PROM & & & & \\
Yes & 6 & 22 & 4.42 & $1.62-13.90$ \\
No & 94 & 78 & Ref & \\
4. Hypertensive disorders of pregnancy & & \\
Yes & 7 & 14 & 3.21 & $1.8-23.6$ \\
No & 93 & 86 & Ref & \\
5. Cesarean section & & & \\
Yes & 20 & 42 & 2.90 & $1.48-5.76$ \\
No & 80 & 58 & Ref & \\
\hline
\end{tabular}

Note: Odds ratio of 1.00 .

Abbreviation: PROM, Premature rupture of membranes. 
As shown in Table 3, the risk of a twin pregnancy being delivered prematurely was about 6.5 times that of a singleton (OR: 6.47, CI: 2.70-17.05), and the risk of delivering low birth weight babies was also increased to over nine times that of the risk in singleton deliveries (OR: 9.33, CI: 4.35-20.95). The risk of babies in twin gestation having low Apgar scores was six times (OR: 6.00, CI: 2.67-14.39) while the risk of perinatal death among twin babies was more than 2.5 times that of singleton babies (OR: 2.54, CI: 1.07-6.36).

\section{Discussion}

The incidence of twin pregnancy varies widely throughout the world. The highest incidence has been reported in blacks of West African descent and the lowest in Asian Mongolians. ${ }^{1,2}$ In this study, the incidence of twin deliveries was 1:29.6 (3.37\%). This was higher than that reported in different regions in Nigeria such as in Jos $(1: 43),{ }^{2}$ Iyielu (1:35.5), ${ }^{1}$ Calabar $(1: 37.7),{ }^{7}$ Benin city $(1: 43),{ }^{5}$ and Maiduguri (1:69.4). ${ }^{8}$ It is also much higher than that reported in Europe (1.5\% in UK), 1:80 in Northern America, ${ }^{9}$ and 1:100 in Saudi Arabia. ${ }^{10}$ Therefore, twinning can be said to vary among races and ethnic groups and this may be due to genetic influences.

There was an increase in the incidence of twinning among the Igbo women, as shown in the work done by Adinma and Agbai ${ }^{1}$ which is in the same region as this present study. In the Adinma and Agbai study, the incidence was 1:35.5 as compared to the incidence in this study, which was 1:29.6 (10 years later). This difference may be explained by the increasing use of ovulation induction drugs in the management of infertility and/or the increase in the postponement of pregnancy until the thirties as women increasingly pursue careers before childbearing.

Table 3 Comparison of obstetric outcome in singleton and twin deliveries

\begin{tabular}{|c|c|c|c|c|}
\hline Variables & Singleton & Twin & Odds ratio & $95 \% \mathrm{Cl}$ \\
\hline \multicolumn{5}{|c|}{ I. Preterm delivery } \\
\hline Yes & 8 & 36 & 6.47 & $2.70-17.05$ \\
\hline No & 92 & 64 & Ref & \\
\hline \multicolumn{5}{|c|}{ 2. Low birth weight } \\
\hline Yes & 12 & 56 & 9.33 & $4.35-20.95$ \\
\hline No & 88 & 44 & Ref & \\
\hline \multicolumn{5}{|c|}{ 3. Low Apgar score } \\
\hline Yes & 10 & 40 & 6.00 & $2.67-14.39$ \\
\hline No & 90 & 60 & Ref & \\
\hline \multicolumn{5}{|c|}{ 4. Perinatal death } \\
\hline Yes & 10 & 22 & 2.54 & $1.07-6.36$ \\
\hline No & 90 & 78 & Ref & \\
\hline
\end{tabular}

Note: Odds ratio of 1.00
Increasing maternal age and parity have been found to be strongly associated with increased incidence of twinning. ${ }^{1,2,11}$ These findings have been corroborated by this study. The mean maternal age in the twin group was $30 \pm 2.33$ years as compared with $27 \pm 4.7$ years for the singletons. This agrees with the study done in Calabar, Nigeria. ${ }^{7}$ Most studies have found that the incidence of twinning increases with advanced maternal age up till 35 years after which the rate declines. ${ }^{10,11}$

Furthermore, the incidence of twinning increases with parity. For instance, in this study, the mean parity for twin pregnancies was $2.7 \pm 2.33$ while that of singletons was $1.96 \pm 1.87$. It is important to note the increase in both parity and maternal age as risk factors for twinning. The question that arises from this finding is: are they independent risk factors for twinning? The issue of whether parity or gravidity is more influential in twinning has not been fully studied.

The incidence of hypertensive disorders of pregnancy was significantly higher in twin pregnancies. ${ }^{7,9}$ This has been attributed to exposure to superabundant chorionic villi in twin pregnancies. ${ }^{12}$ In this study, $14 \%$ of twin pregnancies had hypertensive disorders of pregnancy as compared with $7 \%$ in singleton pregnancies. This finding was in agreement with the case-control study by Santima and colleagues ${ }^{13}$ in which 187 twin pregnancies and 187 singleton pregnancies were matched for maternal age, parity, and gestational age at delivery. The incidence of hypertensive disorders was significantly higher in women that had twin pregnancies than in their singleton counterparts ( $15 \%$ vs $6 \%$ respectively).

The rate of cesarean section in the delivery of twin pregnancies was statistically higher than that in singleton pregnancies ( $42 \%$ vs $20 \%$ ). The rate of cesarean section in twin pregnancy of $42 \%$ agrees with other studies in Nigeria such as $41.3 \%$ in $\mathrm{Jos}^{2}$ and $36.6 \%$ in Enugu. ${ }^{6}$ The increase in the use of cesarean section to deliver twin pregnancies may be due to increased incidence of other obstetric indications for cesarean deliveries such as hypertensive disorders, malpresentation, cord presentation/prolapse, and premature rupture of membranes as observed in this study.

The common fetal complications observed were low birth weight and preterm deliveries. This comparatively lower birth weight in twin deliveries than in singletons suggest that the degree of fetal distress and growth restriction occurring in utero is probably not unconnected with competition for available nutrients, although this is more evident after a gestational age of 30-34 weeks. Also, other pregnancy complications associated with twin pregnancies such as hypertension and anemia take their toll on the fetal weight. 
This was more obvious in areas where malaria is endemic along with malnutrition.

The increased rate of perinatal death observed in twin pregnancies may be explained by the increased rate of intrauterine growth restrictions, premature rupture of membranes, preterm deliveries, low birth weight, and low Apgar scores among the twin deliveries. ${ }^{1,2,5}$ The higher perinatal mortality observed in this study among twin deliveries compared with singletons probably signified the overall hazard accompanying twin deliveries.

It is hoped that in light of these findings, periodic reviews will be done in the next decade. During this period, some modalities will be put in place to reduce the incidence of unfavorable outcomes associated with twin gestation.

In conclusion, the incidence of twin pregnancy over the study period was high and associated with pregnancy complications and poor obstetric outcomes. Close antenatal and intrapartum care are needed in order to improve on the obstetric outcomes and decrease the complications associated with twin pregnancy.

\section{Disclosure}

The authors had no conflicts of interest in performing the research. The authors alone are responsible for the contents and writing of the paper. They have conducted this study in the course of their service in the hospital and have not received funding from any organization.

\section{References}

1. Adinma JI, Agbai AO. Multiple birth in Nigerian Igbo women; incidence and outcomes. J Obstet Gynaecol. 1997;17(1):42-44.

2. Mutihir JE, Pam VC. Obstetric outcome of twin pregnancies in Jos, Nigeria: a 16 month review in Jos University Hospital, Nigeria. Niger J Clin Pract. 2007;10(1):15-18.

3. Patel F, Hall DR. Twin pregnancies, risks and complications: a review article. Obstetrics and Gynecology Forum. 2004;14(3):13-19.

4. Rao A, Sairam S, Shehata H. Obstetric Complication of twin pregnancies. Best Pract Res Clin Obstet Gynaecol. 2004;18(4):557-576.

5. Onyiriuka AN. Twin delivery, comparison of incidence and fetal outcome in Health Institutions in Benin City, Nigeria. Nig Q J Hosp Med. 2003;16(3):88-92.

6. Onwuzuruike BK, Onah HE. Caesarean section in twin pregnancies in Enugu, Nigeria. Journal of College of Medicine. 2004;9(1):8-11.

7. Bassey EA, Abasiattai AM, Udoma EJ, Asuquo EE. Outcome of twin pregnancies in Calabar, Nigeria. G J Med Sci. 2004;3(1-2):13-15.

8. Nwobodo EI, Bohzom DN, Obed J. Twin births at University of Maiduguri Teaching Hospital: incidence, pregnancy complications and outcome. Nigeria J Med. 2002;11(2):67-69.

9. Bush MC, Pernoll ML. Multiple Pregnancy. In: Decherney AH (editor). Current Diagnosis Treatment in Obstetrics and Gynecology. 10th edition. New York: McGraw-Hill Medical Publishing Division. 2007:310.

10. Al Mulhim A. The epidemiology and antenatal complications of twin gestation; an 8-year review. Bahrain Medical Bulletin. 2001; 23(2):56-60.

11. Abudu OO, Anorlu RI. Multiple pregnancies. In: Akin A (editor). Textbook of Obstetrics and Gynaecology for Medical Students. Nigeria: Heinemann Educational Books; 2005:373-380.

12. Gary CF, Kenneth LJ, Steven BL, John HC, Larry G, Katharine WD. Multifetal Gestation. New York: McGraw-Hill Medical Publishing Division. 2005:911-948.

13. Santema JG, Koppelaar I, Waltenbury HC. Hypertensive disorders in twin pregnancy. Eur J Obstet Gynecol Reprod Biol. 1995;58(1):9-13.
International Journal of Women's Health

\section{Publish your work in this journal}

The International Journal of Women's Health is an international, peerreviewed open-access journal publishing original research, reports, reviews and commentaries on all aspects of women's healthcare including gynecology, obstetrics, and breast cancer. Subject areas include: Chronic conditions (migraine headaches, arthritis, osteoporosis);

\section{Dovepress}

Endocrine and autoimmune syndromes; Sexual and reproductive health; Psychological and psychosocial conditions. The manuscript management system is completely online and includes a very quick and fair peer-review system. Visit http://www.dovepress.com/ testimonials.php to read real quotes from published authors. 